Article

\title{
Levels of Angiotensin-Converting Enzyme and Apolipoproteins Are Associated with Alzheimer's Disease and Cardiovascular Diseases
}

\author{
Chun Xu ${ }^{1, *(D)}$, Debra Garcia ${ }^{1}$, Yongke Lu ${ }^{2}$, Kaysie Ozuna ${ }^{1}$, Donald A. Adjeroh ${ }^{3}$, Kesheng Wang ${ }^{4, *}$ \\ and on behalf of the Alzheimer's Disease Neuroimaging Initiative ${ }^{\dagger}$
}

1 Department of Health and Biomedical Sciences, College of Health Professions, University of Teas Rio Grande Valley, Brownsville, TX 78520, USA; debra.garcia03@utrgv.edu (D.G.); kaysie.ozuna01@utrgv.edu (K.O.)

2 Department of Biomedical Sciences, Joan C. Edwards School of Medicine, Marshall University, Huntington, WV 25755, USA; luy@marshall.edu

3 Lane Department of Computer Science \& Electrical Engineering, West Virginia University, Morgantown, WV 26506, USA; don@csee.wvu.edu

4 Department of Family and Community Health, School of Nursing, West Virginia University, Morgantown, WV 26506, USA

* Correspondence: chun.xu@utrgv.edu (C.X.); kesheng.wang@hsc.wvu.edu (K.W.); Tel.: +1-956-882-4193 (C.X.); +1-304-581-1912 (K.W.)

+ A complete listing of ADNI investigators can be found in Acknowledgment.

Citation: Xu, C.; Garcia, D.; Lu, Y.; Ozuna, K.; Adjeroh, D.A.; Wang, K.; on behalf of the Alzheimer's Disease Neuroimaging Initiative. Levels of Angiotensin-Converting Enzyme and Apolipoproteins Are Associated with Alzheimer's Disease and Cardiovascular Diseases. Cells 2022, 11,29. https://doi.org/10.3390/ cells11010029

Academic Editor: Alexander E. Kalyuzhny

Received: 11 November 2021 Accepted: 17 December 2021 Published: 23 December 2021

Publisher's Note: MDPI stays neutral with regard to jurisdictional claims in published maps and institutional affiliations.

Copyright: (c) 2021 by the authors. Licensee MDPI, Basel, Switzerland. This article is an open access article distributed under the terms and conditions of the Creative Commons Attribution (CC BY) license (https:// creativecommons.org/licenses/by/ $4.0 /)$.

\begin{abstract}
Angiotensin-converting enzyme-1 (ACE1) and apolipoproteins (APOs) may play important roles in the development of Alzheimer's disease (AD) and cardiovascular diseases (CVDs). This study aimed to examine the associations of $\mathrm{AD}, \mathrm{CVD}$, and endocrine-metabolic diseases (EMDs) with the levels of ACE1 and 9 APO proteins (ApoAI, ApoAII, ApoAIV, ApoB, ApoCI, ApoCIII, ApoD, ApoE, and $\mathrm{ApoH}$ ). Non-Hispanic white individuals including 109 patients with AD, 356 mild cognitive impairment (MCI), 373 CVD, 198 EMD and controls were selected from the Alzheimer's Disease Neuroimaging Initiative (ADNI) dataset. Multivariable general linear model (GLM) was used to examine the associations. ApoE $\varepsilon 4$ allele was associated with AD, as well as ApoAIV, ApoB and ApoE proteins, but not associated with CVD and EMD. Both AD and CVD were associated with levels of ACE1, ApoB, and ApoH proteins. AD, MCI and EMD were associated with levels of ACE1, ApoAII, and ApoE proteins. This is the first study to report associations of ACE1 and several APO proteins with $\mathrm{AD}, \mathrm{MCI}, \mathrm{CVD}$ and EMD, respectively, including upregulated and downregulated protein levels. In conclusion, as specific or shared biomarkers, the levels of ACE1 and APO proteins are implicated for $\mathrm{AD}, \mathrm{CVD}, \mathrm{EMD}$ and $A p o E \varepsilon 4$ allele. Further studies are required for validation to establish reliable biomarkers for these health conditions.
\end{abstract}

Keywords: Alzheimer's disease; cardiovascular diseases; angiotensin-converting enzyme; apolipoproteins; ApoB; ApoH

\section{Introduction}

Alzheimer's disease (AD) is a progressive disease that affects memory through the degeneration of brain cell connections and the cells themselves [1]. The pathogenesis of AD is associated with abnormal lipid metabolism [2]. Lipids are transported by binding to apolipoproteins. Abnormal aplipoprotein metabolism may lead to an increased clearance by macrophages and result in atherosclerosis. Among the pool of apolipoproteins, apolipoprotein E (ApoE) is well studied, and ApoE is found in plasma as well as in cerebrospinal fluid (CSF). The human $A p o E$ gene is functionally polymorphic and consists of three allele variants- $-\varepsilon 2, \varepsilon 3$, and $\varepsilon 4$ [3]. The $A p o E \varepsilon 3$ allele is the most common allele, followed by $\varepsilon 4$ allele [2]. Due to its distinct role in lipid metabolism, ApoE variants naturally 
influence cholesterol transport and homeostasis. The relation between $A p o E \varepsilon 4$ and CVD might also determine the risk and prevalence of dementia [4]. ApoE absence results in a spike in the plasma cholesterol levels, and the start of atherosclerosis [5]. Indeed, over $60 \%$ of people with $\mathrm{AD}$ have at least one $A p o E \varepsilon 4$ allele [6]. ApoE is detected in the brain [7] and is synthesized at several tissues, and secreted in a variety of cells, and because of its avidity for lipids, it can be secreted in a lipid-poor form [8]. Functions of ApoE involve cholesterol efflux, more specifically involved in cholesterol-loaded macrophage foam cells, and other atherosclerosis-relevant cells [9]. Therefore, $A p o E$ gene is a potential candidate gene, not only for $\mathrm{AD}$, but also for CVD. However, there is limited study of ApoE genetic variants in association with the level of other apolipoproteins (APOs).

Increased studies suggested shared risk factors, pathophysiology and clinical presentations among three common diseases, AD, CVD and endocrine-metabolic diseases (EMD) [10]. Susceptibility to metabolic disturbances and the response to disease are determined by the variations in the genes that code for APOs, including their receptors and their interaction with the environment [11]. CVD is characterized by vessels and atherosclerosis. In CVD, certain $A p o E$ genotypes are responsible for initiating the synthesis in microphages that also cause the formation of high density-like lipoproteins that affect the cholesterol transport to the liver in reverse [12]. Receptors on apolipoproteins serve not only as risk factors for CVD and causes for degeneration of the central nervous system (CNS), but also serve to control lipid metabolism [13], including EMDs, which have been associated with immune system imbalance and in endothelial dysfunction that leads to the impaired control of constricted blood vessels and contributes to the pathogenesis of both CVD and EMD [14]. It is well established that the ApoE protein is associated with processes of lipid metabolism, possibly involved several diseases [8].

Various studies show shared physiological, pathology and clinical manifestations among $\mathrm{AD}, \mathrm{CVD}$, and EMD, while risk factors associated with CVD and a cluster of EMD significantly influence the incidence of AD. For example, imbalanced blood cholesterol levels linked to metabolic disorders have been associated with the risk for AD [15]. Furthermore, the $A p o E \varepsilon 4$ allele is associated with $\mathrm{AD}$, so cholesterol association with APOs is correlated. Genes, environmental factors, and their complex interactions contribute to the development of chronic, multi-factorial health conditions such as AD, CVD, or EMD. Most importantly, studies report shared $A p o E \varepsilon 4$ allele among several chronic health conditions, including $\mathrm{AD}, \mathrm{CVD}$, and metabolic phenotypes [16]. ApoE $\varepsilon 4$ allele increases the risk of coronary heart disease by approximately $40 \%$ [17]. The result of a stimulation between gene-environment interaction would be minor metabolic abnormalities in $\mathrm{AD}$ that could only be measured through a given period [18].

There are limited studies in the associations of biomarkers (e.g., APO protein levels) with AD, CVD, EMD and ApoE gene [19]. The pathogenesis of AD and CVD involves the accumulation of an amyloid-beta (A $\beta$ ) peptides [20]. Angiotensin-Converting Enzyme-1 (ACE1) has been suggested to play a direct role in regulating the degradation of $A \beta$, a recent cross-sectional regression analysis concluded that ACE protein level and CSF activity were significantly lower in subjects with $\mathrm{AD}$ therefore strengthening the hypothesis that $\mathrm{ACE}$ degrades $A \beta$ [21]. The deposition of $A \beta$ causes tissue inflammation and organ dysfunction, including the brain and the heart [22]. The results of a recent study suggest that subclinical cardiac involvement in $\mathrm{AD}$ is likely associated with $\mathrm{A} \beta$ [23]. One connection between $A p o E$ gene and $A \beta$ is that $A p o E$ is a factor that influences the outcome of $A \beta s$ latency in the extracellular space [24]. Since ApoE4 is the most unstable member of the three isoforms, it is known to have poor cholesterol delivery to neurons and is involved in the accumulation of $A \beta$ aggregation. A more detailed analysis of this interaction would show that ApoE binds to at least 3 of the receptors in the CNS. The receptors that can result in the attachment with ApoE protein would be the low-density lipoprotein receptor (LDL-R), very low-density lipoprotein receptor (VLDL-R), and low-density lipoprotein like receptor (LRP) [25]. An earlier study showed that the ApoE $\varepsilon 4$ allele is associated with coronary atherosclerosis 
in $\mathrm{AD}$ patients due to the emergence of the angiotensin-converting enzyme DD genotype (ACE-DD), which is increased as the patient ages [26].

Another key biomarker is ACE enzyme. The ACE gene has become one of the most researched candidate genes for its influence on the risk for hypertension, along with cardiovascular diseases [27]. Moreover, ACE is also responsible for converting angiotensin I to angiotensin II, and increased levels of angiotensin II cerebrovascular constriction and damage lead to an increased risk of AD [28]. Moreover, APOs also show association with AD, CVD, and EMD [29]. More specifically, apolipoprotein B (Apo-B) may be involved in the pathophysiology of $\mathrm{AD}$ and CVD; however, there is limited study on this potential involvement [30]. Atherosclerosis is known to be the most common contributor to CVD, and all the atherogenic lipoproteins have a single Apo-B molecule as their structural protein [31] It has been shown that serum Apo-B, as one biomarker, is a strong predictor of CVD [32] and could play a role in regulating physical function in addition to indirectly impacting the lipid profile [30].

Given the potential links of these protein levels with the diseases discussed above, we hypothesized that levels of ACE1 enzyme and APO proteins, as potential biomarkers may be involved in the developments of $\mathrm{AD}, \mathrm{CVD}$ and EMD via abnormal cholesterol efflux, cholesterol transport, immune system imbalance and/or in endothelial dysfunction. However, there has been limited, at times contradictory, studies on the interplay between ApoE alleles and the levels of these ten proteins (one ACE1, nine APOs; namely, ApoAI, ApoAII, ApoAIV, ApoB, ApoCI, ApoCIII, ApoD, ApoE, and ApoH) with AD, CVD, and EMD. Therefore, the aim of the present study is to examine the associations of $A p o E$ gene, $\mathrm{AD}, \mathrm{CVD}$ and EMD with the levels of ACE1 and the nine APOs.

\section{Materials and methods}

\subsection{Study Subjects}

Data used in the preparation of this article were obtained from the Alzheimer's Disease Neuroimaging Initiative (ADNI) database (adni.loni.usc.edu, accessed on 17 May 2021). The ADNI was launched in 2003 as a public-private partnership. The primary goal of ADNI has been to test whether serial magnetic resonance imaging (MRI), positron emission tomography (PET), other biological markers, and clinical and neuropsychological assessments can be combined to measure the progression of mild cognitive impairment (MCI) and early AD. The ADNI study began in 2004 as a multicenter that provides services to the United States and Canada. The ADNI is an ongoing, longitudinal, multicenter study designed to develop clinical, imaging, genetic, and biochemical biomarkers for the early detection and tracking of AD. For this study, the merged data were used from several components of ADNI. There was an Institutional Review Board exemption for current study due to secondary data analysis.

\subsection{Measures}

Demographic variables included age, gender, and educational levels. Gender was self-reported as either male or female. Age and education were continuous variables in years. All individuals in the present study are non-Hispanic white. AD was diagnosed using NINCDS / ADRDA criteria for probable AD [33]. There were 109 individuals with $\mathrm{AD}, 356$ with $\mathrm{MCI}$, and 53 with cognitive normal $(\mathrm{CN})$ as control subjects. CVD and EMD were from data (MedHist) in ADNI. Diagnoses for 373 CVD and 198 EMD were based on self-reported on CVD and EMD were defined as Yes (with CVD or EMD disease histories, respectively) or No (without these two disease histories, respectively) (Table 1). 
Table 1. Descriptive statistics.

\begin{tabular}{|c|c|c|c|c|c|c|}
\hline Variable & $\begin{array}{l}\text { AD vs. MCI vs. CN } \\
\text { Mean } \pm \text { SD } \\
\text { or Count }\end{array}$ & $F / \chi^{2}, p$ & $\begin{array}{l}\text { CVD vs. Non-CVD } \\
\text { Mean } \pm \text { SD } \\
\text { or Count }\end{array}$ & $t / \chi 2, p$ & $\begin{array}{c}\text { EMD vs. Non-EMD } \\
\text { Mean } \pm \text { SD } \\
\text { or Count }\end{array}$ & $t / \chi^{2}, p$ \\
\hline$N$ & 109 vs. 356 vs. 53 & & 373 vs. 145 & & 198 vs. 320 & \\
\hline Age & $\begin{array}{l}74.9 \pm 8.0 \\
75.1 \pm 7.3 \\
75.4 \pm 5.7\end{array}$ & $0.09,0.9176$ & $\begin{array}{l}75.4 \pm 7.2 \\
74.3 \pm 7.7\end{array}$ & $1.60,0.1099$ & $\begin{array}{l}75.5 \pm 6.9 \\
74.8 \pm 7.6\end{array}$ & $1.08,0.2820$ \\
\hline \multicolumn{7}{|l|}{ Gender } \\
\hline Male & 64 vs. 232 vs. 28 & $3.86,0.1449$ & 244 vs. 80 & $4.68,0.0306$ & 115 vs. 209 & $2.73,0.0984$ \\
\hline Female & 45 vs. 124 vs. 25 & & 129 vs. 65 & & 83 vs. 111 & \\
\hline Edu & $\begin{array}{l}15.2 \pm 3.1 \\
15.7 \pm 3.0 \\
15.9 \pm 2.7\end{array}$ & $1.55,0.2134$ & $\begin{array}{l}15.5 \pm 3.0 \\
15.9 \pm 2.8\end{array}$ & $-1.17,0.2407$ & $\begin{array}{l}15.5 \pm 3.0 \\
15.7 \pm 2.9\end{array}$ & $-0.82,0.4141$ \\
\hline \multicolumn{7}{|l|}{ ApoE $\varepsilon 4$ allele } \\
\hline $\begin{array}{c}0 \\
1+\end{array}$ & $\begin{array}{l}36 \text { vs. } 164 \text { vs. } 49 \\
73 \text { vs. } 192 \text { vs. } 4\end{array}$ & $52.28,<0.0001$ & $\begin{array}{l}177 \text { vs. } 72 \\
196 \text { vs. } 73\end{array}$ & $0.20,0.6524$ & $\begin{array}{l}98 \text { vs. } 151 \\
100 \text { vs. } 169\end{array}$ & $0.26,0.6095$ \\
\hline
\end{tabular}

Abbreviations: AD: Alzheimer disease; $\mathrm{CN}$ : Cognitive normal; MCI: Mild cognitive impairment; CVD: Cardiovascular disease, non-CVD; EMD: Endocrine-metabolic diseases, non-EMD; SD: Standard deviation. $p$ value is based on Chi-square test or $\mathrm{F}$ test or $\mathrm{t}$ test in ANOVA. Due to missing values, the total number for some variables was less than 518

The data of $A p o E$ genotypes were extracted from the ADNI database. ApoE $\varepsilon 4$ genotyping was performed on DNA samples obtained from subjects' blood, using an ApoE genotyping kit. The two SNPs characterizing ApoE $\varepsilon 2 / \varepsilon 3 / \varepsilon 4$ status (rs429358 and rs7412) were genotyped separately and merged with the array data sets. ApoE $\varepsilon 4$ carriers were defined as individuals with at least one $\varepsilon 4$ allele ( $\varepsilon 4 / \varepsilon 4$ designated as $A p o E-\varepsilon 4-2, \varepsilon 4 / \varepsilon 3$ or $\varepsilon 4 / \varepsilon 2$ as $A p o E-\varepsilon 4-1+)$, while non-carriers were defined as individuals with no $\varepsilon 4$ allele (ApoE \&4-0) (Table 1).

The data on ACE1 and APOs were from a subset of "Biomarkers Consortium Plasma Proteomics Project RBM multiplex data" in ADNI. In the present study, we selected 10 proteins, namely, ACE1 and 9 APO proteins (ApoAI, ApoAII, ApoAIV, ApoB, ApoCI, ApoCIII, ApoD, ApoE, and ApoH). After merging demographic variables, AD diagnosis, medical history variables, $A p o E$ genotypes and protein data, the total sample size is 518 (Table 1), including 109 with $\mathrm{AD}, 356$ with $\mathrm{MCI}$, and 53 with $\mathrm{CN}$ (cognitive normal). There are a total of 373 patients with CVD, 145 subjects without CVD (called non-CVD), as well as 198 patients with EMD and 320 subjects without EMD (called non-EMD).

\subsection{Statistical Methods}

The categorical variables were presented in their raw values along with the proportions for categorical variables. Continuous variables such as age and education are presented in the form of mean $\pm \mathrm{SD}$. Chi-square test was used to examine the associations of categorical variables with $\mathrm{AD}$ diagnosis, CVD, and EMD. One-way ANOVA was performed to determine differences in continuous variables among AD diagnosis, CVD, and EMD status.

The distributions of protein levels may be skewed. The $Z$ score was computed for each protein using the mean and standard deviation. Values with a $\mathrm{Z}$ score greater than 3.5 or less than -3.5 were considered as possible outliers [34]. After removing outlier individuals, respective skewness and kurtosis values for each of the 10 proteins were within $(-2,2)$, indicating closeness to normal distributions. The histograms of $\mathrm{Z}$ scores for two proteins are presented in Figures 1 and 2, respectively. 


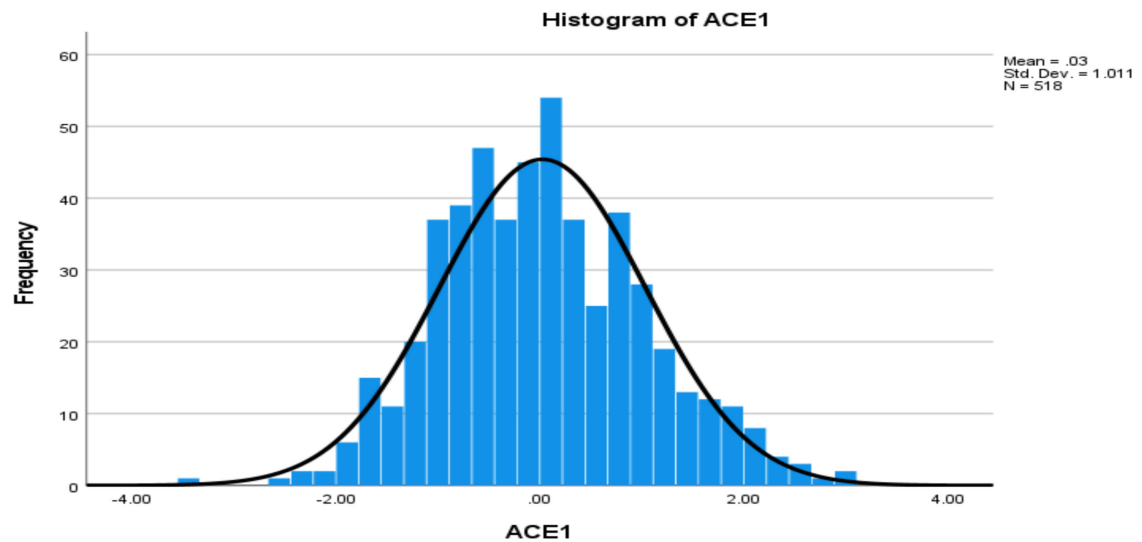

Figure 1. Histogram of angiotensin-converting enzyme 1 (ACE1) with normal curve, based on Z score.

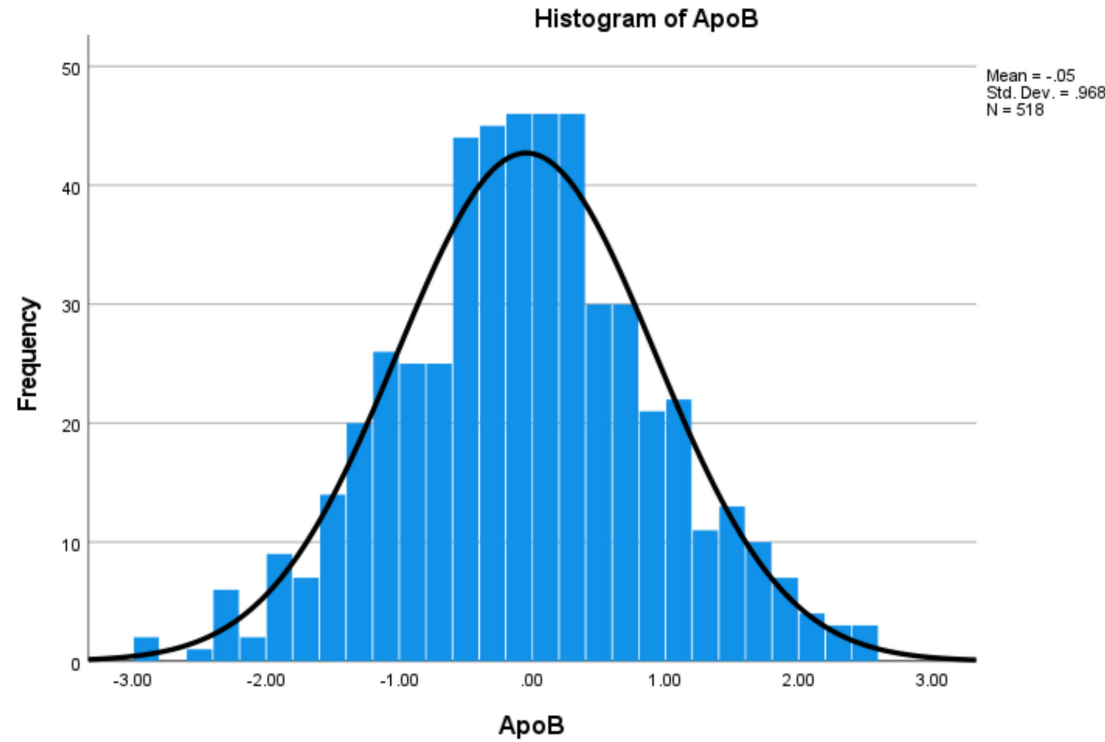

Figure 2. Histogram of ApoB with normal curve based on $\mathrm{Z}$ score.

Pearson and Spearman correlations were computed to test associations among 10 proteins using the $\mathrm{Z}$ scores. To further analyze the relationships among the ten proteins, the VARCLUS procedure in SAS 9.4 (SAS Institute, Cary, CA, USA) was used to explore the potential clusters of variables with strong correlations with each other within a cluster, and weak correlations, with variables in other clusters [35].

Independent samples $t$ test was used to compare the means in each of the ten proteins between two groups with respect to AD vs. CN, MCI vs. CN, CVD vs. non-CVD, EMD vs. non-EMD, and ApoE \&4-1+ vs. ApoE \&4-0. Then, the multivariable general linear model (GLM) was used to examine the associations of ApoE genotypes, AD, CVD, and EMD with each of the 10 proteins, adjusted for age, gender and education. All statistical analyses were performed using SAS (version 9.4).

\section{Results}

\subsection{Descriptive Statistics}

Age, gender, and education level were not associated with AD diagnosis $(p=0.9176$, 0.1449 and 0.2134 , respectively), however, a significant association was observed of $A p o E$ $\varepsilon 4$ allele with AD diagnosis $(p<0.0001)$ (Table 1$)$. There were no significant associations between CVD diagnostic status and age, education level, and $A p o E \varepsilon 4$ allele, but a significant difference was observed between gender and CVD diagnosis $(p=0.0306)$. There was no association of EMD diagnosis with age, gender, education, and $A p o E \varepsilon 4$ allele. 


\subsection{Correlation Analysis and Variable Cluster Analysis}

Pearson and Spearman correlation coefficients for 10 proteins are presented in Table 2. A total of 10 proteins were clustered into four clusters (Figure 3): ApoAII, ApoCI, ApoCIII, and ApoE (cluster 1), ApoB and ApoH (cluster 2), ACE1 (cluster 3), and ApoAI, ApoAIV and ApoD (cluster 4). Four clusters could explain $60.5 \%$ of the total variance. Table 2 displays the strong correlation between variables of ten proteins within clusters.

Table 2. Correlation analysis of ten proteins.

\begin{tabular}{ccccccccccc}
\hline Variable & ACE1 & ApoAI & ApoAII & ApoAIV & ApoB & ApoCI & ApoCIII & ApoD & ApoE & ApoH \\
\hline \multirow{2}{*}{ ACE1 } & 1 & -0.0567 & 0.0818 & 0.1056 & 0.0039 & -0.0381 & 0.0914 & -0.0021 & 0.0375 & 0.0235 \\
& & 0.1976 & 0.0629 & 0.0162 & 0.9291 & 0.3870 & 0.0377 & 0.9626 & 0.3949 & 0.5936 \\
\hline \multirow{2}{*}{ ApoAI } & -0.0515 & 1 & 0.3045 & 0.1378 & -0.0941 & 0.4660 & 0.1845 & 0.3811 & 0.1096 & 0.0150 \\
& 0.2418 & & $<0.0001$ & 0.0017 & 0.0323 & $<0.0001$ & $<0.0001$ & $<0.0001$ & 0.0126 & 0.7328 \\
ApoAII & 0.1004 & 0.3062 & & 0.0094 & 0.1424 & 0.5758 & 0.4626 & -0.0683 & 0.2354 & 0.2035 \\
& 0.0222 & $<0.0001$ & 1 & 0.8302 & 0.0012 & $<0.0001$ & $<0.0001$ & 0.1204 & $<0.0001$ & $<0.0001$ \\
ApoAIV & 0.1055 & 0.1612 & -0.0139 & & 0.0410 & -0.0142 & 0.0446 & 0.1037 & -0.0119 & 0.0752 \\
& 0.0163 & 0.0002 & 0.7562 & 1 & 0.3518 & 0.7471 & 0.3112 & 0.0182 & 0.7870 & 0.0874 \\
ApoB & -0.0223 & -0.1117 & 0.1317 & 0.0198 & & 0.2989 & 0.2126 & 0.0156 & 0.2269 & 0.2044 \\
& 0.6128 & 0.0109 & 0.0027 & 0.6536 & 1 & $<0.0001$ & $<0.0001$ & 0.7227 & $<0.0001$ & $<0.0001$ \\
ApoCI & -0.0199 & 0.4548 & 0.5698 & -0.0294 & 0.2815 & 1 & 0.5908 & 0.1934 & 0.4515 & 0.2111 \\
& 0.6519 & $<0.0001$ & $<0.0001$ & 0.5037 & $<0.0001$ & 1 & $<0.0001$ & $<0.0001$ & $<0.0001$ & $<0.0001$ \\
ApoCIII & 0.0930 & 0.1845 & 0.4820 & 0.0089 & 0.1951 & 0.6041 & 1 & -0.0242 & 0.4438 & 0.2170 \\
& 0.0343 & $<0.0001$ & $<0.0001$ & 0.8396 & $<0.0001$ & $<0.0001$ & 1 & 0.5831 & $<0.0001$ & $<0.0001$ \\
ApoD & 0.0021 & 0.3740 & -0.0799 & 0.1270 & -0.0204 & 0.1817 & -0.0216 & 1 & 0.1151 & 0.0756 \\
& 0.9620 & $<0.0001$ & 0.0689 & 0.0038 & 0.6430 & $<0.0001$ & 0.6242 & 1 & 0.0087 & 0.0857 \\
ApoE & 0.0381 & 0.1077 & 0.2637 & -0.0425 & 0.2303 & 0.4518 & 0.4503 & 0.1305 & 1 & 0.1419 \\
& 0.3867 & 0.0142 & $<0.0001$ & 0.3340 & $<0.0001$ & $<0.0001$ & $<0.0001$ & 0.0029 & 0.0012 \\
ApoH & 0.0481 & -0.0047 & 0.2453 & 0.0753 & 0.1743 & 0.1998 & 0.2529 & 0.0038 & 0.1366 & 1 \\
& 0.2744 & 0.9154 & $<0.0001$ & 0.0869 & $<0.0001$ & $<0.0001$ & $<0.0001$ & 0.9320 & 0.0018 &
\end{tabular}

Above the diagonal is the Pearson correlation coefficient; below the diagonal is Spearman correlation coefficient. Lower value in each cell denotes the $p$-value.

Name of Variable or Cluster

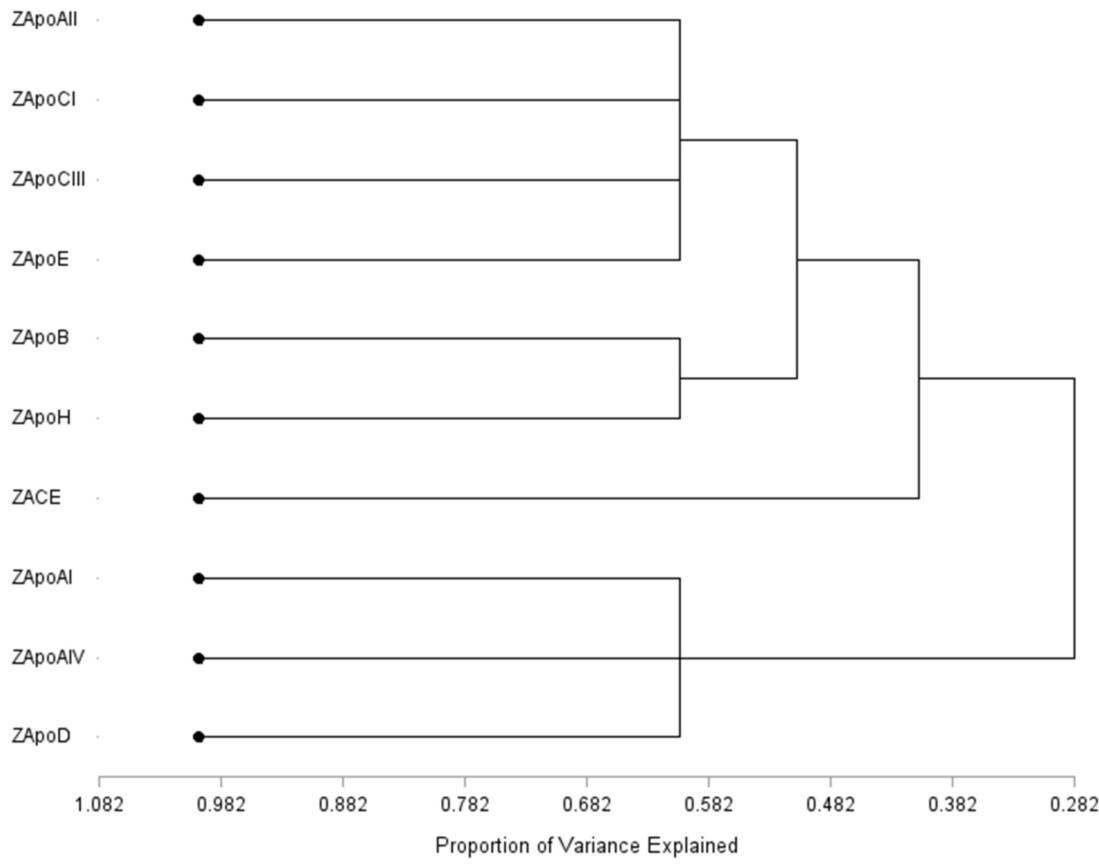

Figure 3. Variable cluster analysis of ten proteins. 


\subsection{Comparison of Means Using Independent Samples $t$ Test}

Initial analysis was performed to compare means between two groups of each of the 10 proteins using independent $t$ test without adjusting for potential covariates. Results are shown in Table 3. There were significant differences between AD and CN in several biomarkers, including ACE1, ApoAII, ApoB, ApoCIII, ApoE and ApoH ( $p$ values $<0.05$, Table 3). Similarly, there were significant differences between MCI and CN in several biomarkers, namely, ACE1, ApoAII, ApoAIV, ApoCI, ApoCIII, ApoD and ApoE. Between CVD and non-CVD, significant differences were observed in four biomarkers, namely, ACE1, ApoAI, ApoB, and ApoH. Additionally, there were significant differences in ApoAII and ApoD between EMD and non-EMD. Moreover, statistically significant differences were found between $A p o E \varepsilon 4$ allele(s) in ApoB and ApoE proteins.

Table 3. Comparison of means using independent samples $t$-test.

\begin{tabular}{cccccc}
\hline \multirow{2}{*}{ Variable } & AD vs. CN & MCI vs. CN & CVD vs. Non-CVD & EMD vs. Non-EMD & ApoE $\varepsilon 4-1+v s ~ 0$ \\
& $\boldsymbol{t}, \boldsymbol{p}$ & $\boldsymbol{t} \boldsymbol{p}$ & $\boldsymbol{t}, \boldsymbol{p}$ & $\boldsymbol{t} \boldsymbol{p}$ & $\boldsymbol{t} \boldsymbol{p} \boldsymbol{p}$ \\
\hline ACE1 & $-2.64,0.0085$ & $-2.67,0.0077$ & $4.59,<0.0001$ & $2.39,0.0174$ & $-0.72,0.4724$ \\
ApoAI & $0.84,0.4030$ & $-0.57,0.5681$ & $-2.22,0.0266$ & $-0.65,0.5186$ & $-1.55,0.1219$ \\
ApoAII & $-4.43,<0.0001$ & $-6.17,<0.0001$ & $0.42,0.6752$ & $2.43,0.0156$ & $-1.84,0.0661$ \\
ApoAIV & $1.64,0.1016$ & $3.60,0.0004$ & $0.48,0.6344$ & $0.08,0.9345$ & $-1.09,0.2755$ \\
ApoB & $2.95,0.0033$ & $1.03,0.3025$ & $-2.37,0.0182$ & $-0.74,0.4607$ & $3.20,0.0015$ \\
ApoCI & $0.94,0.3458$ & $-2.90,0.0039$ & $-1.77,0.0733$ & $-0.03,0.9776$ & $-0.83,0.4057$ \\
ApoCIII & $-2.76,0.0059$ & $-2.46,0.0141$ & $1.48,0.1392$ & $1.56,0.1190$ & $-1.45,0.1475$ \\
ApoD & $0.37,0.7113$ & $-2.82,0.0050$ & $-1.42,0.1564$ & $-2.50,0.0126$ & $-1.55,0.1226$ \\
ApoE & $-5.05,<0.0001$ & $-6.88,<0.0001$ & -1.83 .0 .0675 & $-1.76,0.0794$ & $-10.73,<0.0001$ \\
ApoH & $3.05,0.0024$ & $-0.49,0.6222$ & $2.99,0.0029$ & $1.56,0.1191$ & $0.05,0.9580$ \\
\hline
\end{tabular}

Abbreviations: AD: Alzheimer disease; CN: Cognitive normal; MCI: Mild cognitive impairment; CVD: Cardiovascular disease; EMD: Endocrine-metabolic diseases; ACE1: Angiotensin-converting enzyme 1. $p$ value is based on independent samples $t$ test.

\subsection{Analysis Using Multivariable General Linear Model (GLM)}

To adjust for potential covariates, multivariable GLM was used. Table 4 shows the results. AD, MCI, CVD and EMD maintained significant associations with ACE1 protein ( $p=0.0093,0.0091,<0.0001$ and 0.0265, respectively). AD, CVD and ApoE $\varepsilon 4$ allele showed significant associations with ApoB protein ( $p=0.0448,0.0233$ and 0.0255 , respectively); while AD and CVD showed associations with $\mathrm{ApoH}$ protein $(p=0.0031$ and 0.0107 , respectively). Furthermore, AD, MCI and EMD revealed significant associations with ApoAII protein ( $p=<0.0001,<0.0001$ and 0.0193, respectively); while AD, MCI, EMD and ApoE $\varepsilon 4$ allele showed strong associations with ApoE protein $(p=0.0306,<0.0001,0.0115$ and $<0.0001$, respectively)

Table 4. Multivariable GLM for ten proteins.

\begin{tabular}{|c|c|c|c|c|c|}
\hline Variable & $\begin{array}{c}\text { AD vs. CN } \\
t, p\end{array}$ & $\begin{array}{c}\text { MCI vs. CN } \\
t, p\end{array}$ & $\begin{array}{c}\text { CVD vs. Non-CVD } \\
t, p\end{array}$ & $\begin{array}{c}\text { EMD vs. Non-EMD } \\
t, p\end{array}$ & $\begin{array}{c}\text { ApoE } \varepsilon 4-1+\text { vs. } 0 \\
t, p\end{array}$ \\
\hline ACE1 & $-2.61,0.0093$ & $-2.62,0.0091$ & $4.40,<0.0001$ & $2.22,0.0265$ & $0.02,0.0 .9863$ \\
\hline ApoAI & $191,0.0573$ & $0.66,0.5089$ & $-1.20,0.2319$ & $-1.37,0.1728$ & $-1.65,0.1004$ \\
\hline ApoAII & $-4.12,<0.0001$ & $-5.66,<0.0001$ & $0.82,0.4127$ & $2.35,0.0193$ & $-0.50,0.6166$ \\
\hline ApoAIV & $2.30,0.0219$ & $4.12,<0.0001$ & $0.83,0.4054$ & $0.01,0.9975$ & $-2.00,0.0455$ \\
\hline ApoB & $2.01,0.0448$ & $0.32,0.7458$ & $-2.28,0.0233$ & $-0.62,0.5340$ & $2.24,0.0255$ \\
\hline ApoCI & $1.60,0.1011$ & $-2.07,0.0392$ & $-0.82,0.3917$ & $-0.55,0.5797$ & $-1.07,0.2863$ \\
\hline ApoCIII & $-2.42,0.0159$ & $-1.88,0.0608$ & $1.89,0.0594$ & $1.11,0.2686$ & $-0.57,0.5696$ \\
\hline ApoD & $0.86,0.3904$ & $-2.51,0.0124$ & $-1.60,0.1102$ & $-2.43,0.0155$ & $-1.32,0.1860$ \\
\hline ApoE & $-2.17,0.0306$ & $-4.31,<0.0001$ & -1.50 .0 .1333 & $-2.54,0.0115$ & $-9.37,<0.0001$ \\
\hline $\mathrm{ApoH}$ & $2.98,0.0031$ & $-0.45,0.6494$ & $2.56,0.0107$ & $1.28,0.1995$ & $-0.63,0.5280$ \\
\hline
\end{tabular}

Abbreviations: Alzheimer disease; CN: Cognitive normal; MCI: Mild cognitive impairment; CVD: Cardiovascular disease; EMD: endocrine-metabolic diseases; $p$ value is based on $t$ test in multivariable GLM. 


\section{Discussion}

In this study, we examined possible associations of nine APO proteins and one enzyme with three common health conditions and $A p o E \varepsilon 4$ genotype. The main findings of this study include: (1) ACE1 and several APO proteins are associated with AD, CVD and EMD, respectively. To our knowledge, this is the first study of the potential association of the 10 biomarkers (9 APO proteins, 1 enzyme) with the three identified chronic health conditions (AD, CVD, and EMD). (2) The ApoE $\varepsilon 4$ allele is associated with AD and MCI, but not directly associated with CVD and EMD. (3) The ApoE $\varepsilon 4$ allele is positively associated with ApoB level and negatively associated with ApoE level in CSF.

By using a multivariable GLM, we found that ACE1 is associated with the four health conditions (AD, MCI, CVD, and EMD) after controlling for covariates. The observed inverse relationship in the association of ACE with $\mathrm{AD}$ and $\mathrm{MCI}$ in the current study is consistent with previous studies, including one that shows that ACE2 activity is significantly reduced in $\mathrm{AD}$, when compared with age-matched controls from human brain samples [36]. ACE has been suggested to play a direct role in regulating the degradation of $A \beta$. An earlier cross-sectional regression analysis concluded that ACE protein level and CSF activity were significantly lower in subjects with $\mathrm{AD}$, therefore strengthening the hypothesis that ACE degrades A $\beta$ [21]. However, elevated ACE1 level was associated with worse processing speed and a working memory of 18 patients with AD [37], which may be due to differences in sample size (e.g., a small patient population), study design, and different ACE levels (such as ACE 1 or 2). Previous findings suggest that ACE could degrade the B-amyloid. For example, the B-amyloid is one of the pathological markers for AD. The activity of ACE would depend primarily on either the insertion or deletion polymorphism of the $A C E$ gene. The use of ACE inhibitors could slow down the progression and deterioration of cognitive functions in affected individuals [38]. In terms of the association of ACE with CVD, a study of soluble ACE2 showed the positive association of this biomarker with myocardial injury and neurohormonal activation, impaired diastolic function, and CVD [39]. A recent study suggests that higher soluble ACE2 levels were associated with significantly higher biomarkers of cardiac injury [39], which supports our current findings. In terms of ACE associated with metabolic-related disorders, a previous study on 90 patients with diabetes reported that urine ACE2 might potentially function as a marker for monitoring the metabolic status [40], which partially supports the current findings. However, the phenotypes of EMD in the current study are broader (including both endocrine diseases and metabolic diseases) and with a large sample size (total of 198 patients with EMD and 320 non-EMD). To the best of our knowledge, this is the first report of a positive association of ACE1 enzyme level with EMD.

Accumulated evidence, including the current findings, suggest that the ApoE $\varepsilon 4$ allele is associated with $\mathrm{AD}$ [41]. However, there has been only a limited study of ApoE protein level in association with diseases, such as AD [42,43]. The results of this current study provide additional evidence: significant inverse associations of ApoE protein levels with AD, MCI, and EMD, as well as ApoE $\varepsilon 4$ allele. With respect to AD, an inverse association of ApoE protein with AD in the current study is consistent with previous reports in postmortem brain samples [44]. In addition, it has been well established that the ApoE protein modulates the formation of amyloid plaques and neurofibrillary tangles, and that various ApoE isoforms enhance or mitigate AD onset by clear and precise molecular mechanisms [42]. A recent study showed that human CSF from ApoE $\varepsilon 4 / \varepsilon 4$ carriers had a greater percentage of aggregated ApoE protein compared with CSF from ApoE $\varepsilon 3 / \varepsilon 3$ carriers [45]. The results of our current study and previous reports, including the accumulation of $\beta$-amyloid (A $\beta)$ plaques [45], suggest that ApoE protein plays a central role in AD pathology.

With respect to the association of $A p o E \varepsilon 4$ allele and ApoE protein with CVD, the results of the current study suggest that CVD showed borderline significant association with ApoE protein $(p=0.0675$, Table 3$)$, but no association with the $A p o E \varepsilon 4$ allele. The results of a phenome-wide association study (PheWAS) suggest the association of ApoE genotypes 
with disease risks and found consistent evidence of the $A p o E \varepsilon 4$ allele and an elevated risk of multiple CVD [2]. A second cross-sectional study with a total of 924 participants concluded that the population carrying the $A p o E \varepsilon 4$ allele had an increased risk of CVD and type 2 diabetes (T2DM); additionally, these subjects manifested a higher level of lipid profiles [46]. However, the results of our current study did not support ApoE $\varepsilon 4$ allele association with CVD, which may be due to different sample sizes, study designs, and other factors. Due to its distinct role in lipid metabolism, ApoE variants naturally influence cholesterol transport and homeostasis. A recent study suggested that the relation between ApoE $\varepsilon 4$ and CVD can also determine the risk and prevalence of dementia; however, data have many gaps and have been deemed inconsistent [4]. Recent therapeutic approaches of ApoE protein targeted (from the ApoE gene to the ApoE protein and its interactors) have been developed in animal models, which may be ready to be translated to human in the future [47]. The ApoE gene is a promising therapeutic target for those conditions, which remains investigated [47]. Accumulated studies demonstrate that lipid metabolism is involved in health conditions, and the ApoE protein, as a major lipid transporter, plays a key role in the pathogenesis of $\mathrm{AD}$ [43], CVD, and EMD.

Associations of ApoB, ApoCI, ApoCIII, and ApoH were observed with AD, $\mathrm{MCI}, \mathrm{CVD}$ and EMD respectively in the current study, including decreased ApoB protein level in CVD, but increased in $\mathrm{AD}$, which are supported by previous studies. For instance, analyses of incident CVD events showed inverse associations with ApoB [48]. Another study indirectly suggests that $\mathrm{ApoB}$ is associated with $\mathrm{AD}$, based on their observation that all participants with $A p o E \varepsilon 3 / \varepsilon 4$ or $\varepsilon 4 / \varepsilon 4$ alleles had high levels of ApoB [49]. However, several studies showed an increase in ApoB in CVD including one study, which suggested that elevated ApoB serum levels strongly predict early cardiovascular events [50]. Increasing evidence suggests that $A$ poB is known to be a more powerful predictor of CVD than conventional lipids [51,52]. A recent study also suggests that ApoB particles drive the atherosclerotic process that leads to the precursors of clinical events [53].

A considerable amount of data have highlighted that a high level of ApoCIII leads to a high cholesterol level, which may influence CVD risk; however, the results of the current study just showed borderline significant association $(p=0.0594$, Table 4$)$. The findings of inverse association of ApoCIII with $\mathrm{AD}$ are supported by a previous study of patients with $\mathrm{AD}$ [54]. The results of current and previous studies suggest that individuals with low plasma levels of ApoCIII are at risk for AD. In addition, ApoAII (but not ApoAI) was significantly downregulated, and ApoAIV was upregulated in AD and MCI in the current study. From a study of different ApoA proteins, a recent meta-analysis based on 17 case-control-, two cohort-, and three combined case-control studies (a total of 207 AD and mild cognitive) showed that ApoA-I decreased in AD, while ApoAIV increased [55], which partially supports the current findings. However, this study did not include ApoAII. ApoAIV was found to be upregulated in AD and $\mathrm{MCI}$ in our current study. More research is needed to validate the finding, since understanding how changes in cellular cholesterol levels and apolipoprotein homeostasis affect the central nervous system will offer promising novel avenues for the future treatment of neurological disorders [56], such as $\mathrm{AD}$. In addition, there has been limited study of $\mathrm{ApoH}$ in association with diseases. A genetic study suggested that $A p o H$ polymorphism was associated with some serum lipid parameters in the two ethnic groups, and that rs 1801690 near the $\mathrm{ApoH}$ gene might have racial/ethnic and/or gender-specificity [57]. The ApoH acts as a multi-functional glycoprotein in which it has been correlated with negative health outcomes due to their high heritability [58]. The $\mathrm{ApoH}$, as a circulating protein, is bound to the lipoproteins and contributes to atherosclerotic pathways through its immunological response. One study showed that novel CSF proteins were found to have effects on the inferior and middle temporal cortex, including $\mathrm{ApoH}$ in 90 healthy elders [59]. Future validation studies to establish reliable AD biomarkers are needed.

With respect to shared biomarkers among the four conditions (AD, MCI, CVD and EMD), our study showed a strong disease association with $A p o E \varepsilon 4$ allele and ApoE proteins. 
AD and CVD are moderately associated with ApoH and MCI, while CVD has an inverse association with ApoD. These are new results uncovered by this work. However, ApoE $\varepsilon 4$ allele and certain clinical phenotypes have been repeatedly shown to be shared by AD and CVD [10,16]. Its exact mechanism is not yet known, but ApoE binds preferentially to triglyceride-rich, very low density lipoproteins, leading to the downregulation of LDL receptors, which may be involved in CVD development [12]. Previous studies also suggest that structure correctors are considered as a potential therapeutic approach to reduce ApoE $\varepsilon 4$ pathology in both CVD and neurological disorders, including AD [12].

Several factors may result in discrepancies among the findings from these studies: (1) different ethnicities, as this demographic factor could influence protein levels [55], (2) different types of ACE enzymes: for example, reverse association of ACE1 level with $\mathrm{AD}$ in the current study; high expression levels of ACE2 observed in the brain of AD patients [60], (3) different collection tubes for plasma and serum could also contribute to the variation in protein identification by mass spectrometry [61,62], (4) dissimilar protein profiles could be due differences in the sampling procedures [62] and reagents, (5) different stages of AD [55], CVD and EMD among different studies.

We are also aware of strengths and limitations of the present study. Strengths include (1) the comparatively moderate sample size with 109 AD, 356 MCI, 373 CVD, and 198 EMD:

(2) identification of shared ApoE \&4 allele among AD, MCI, CVD, and EMD. To our knowledge, this is the first study on shared disease-associated allele, levels of ACE1 and nine APO proteins in association with these health conditions. Limitations of the study include (1) some patients with AD and MCI, may also suffer from other health conditions (e.g., CVD and/or EMD); (2) phenotypic heterogeneity with high variation could result in the inconclusive accentuation of biomarkers (ApoE $\varepsilon 4$ allele, ACE1, and APO proteins). In the future, we will focus on more specific phenotypes, for instance, by using novel methods of the ADNI-based analysis of imaging data, such as MRIs, or of a fusion of information from both MRIs and proteomic data; (3) although we started with a moderate sample size, after further dividing to $A p o E \varepsilon 41+$ and 0 , the sample sizes could become comparatively small and, as a result, may not be adequately powered to detect genetic variants exerting smaller effects. Therefore, future large-scale studies with meta-analysis studies are needed to validate the current findings.

\section{Conclusions}

Altogether, we have examined ten protein levels in association with AD, MCI, CVD, EMD, and $A p o E \& 4$ allele. To the best of our knowledge, this is the first report of these protein levels (one ACE (namely, ACE1), and nine APOs (namely, ApoAI, ApoAII, ApoAIV, ApoB, ApoCI, ApoCIII, ApoD, ApoE, and ApoH) as biomarkers, either upregulated or downregulated for AD, CVD, and EMD, respectively. We also showed specifically shared $A p o E \varepsilon 4$ allele and ApoE protein among these health conditions. In addition, shared ApoB and $\mathrm{ApoH}$ biomarkers in AD and CVD were identified. Further integrating the current findings could be useful for validation and/or confirmation studies to establish reliable disease biomarkers.

Author Contributions: Conceptualization: K.W. and C.X.; methodology: K.W., C.X. and D.A.A.; data analysis and interpretation: K.W., Y.L. and D.A.A.; investigation: K.W. and C.X.; funding acquisition, D.A.A.; writing—original draft preparation: K.W., C.X., D.G. and K.O.; writing-review and editing: all authors; supervision: K.W. and C.X. All authors have read and agreed to the published version of the manuscript.

Funding: This work is supported in part by funds from the US National Science Foundation (NSF: \# 1920920) (D.A.A.).

Institutional Review Board Statement: Each ADNI site received institutional review board (IRB) individually. There was an Institutional Review Board exemption for current study due to secondary data analysis. 
Informed Consent Statement: Informed consent was obtained from all subjects involved in the original study. Data used in the preparation of this article were obtained from the Alzheimer's Disease Neuroimaging Initiative (ADNI) database (adni.loni.usc.edu).

Data Availability Statement: Data used in the preparation of this article were obtained from the Alzheimer's Disease Neuroimaging Initiative (ADNI) database (adni.loni.usc.edu).

\begin{abstract}
Acknowledgments: The present study is a secondary data analysis. The original study and ADNI were funded by the Alzheimer's Disease Neuroimaging Initiative (ADNI) (National Institutes of Health Grant U01 AG024904) and DOD ADNI (Department of Defense award number W81XWH12-2-0012). ADNI is funded by the National Institute on Aging, the National Institute of Biomedical Imaging and Bioengineering, and through generous contributions from the following: AbbVie, Alzheimer's Association; Alzheimer's Drug Discovery Foundation; Araclon Biotech; BioClinica, Inc.; Biogen; Bristol-Myers Squibb Company; CereSpir, Inc.; Cogstate; Eisai Inc.; Elan Pharmaceuticals, Inc.; Eli Lilly and Company; EuroImmun; F. Hoffmann-La Roche Ltd. and its affiliated company Genentech, Inc.; Fujirebio; GE Healthcare; IXICO Ltd.; Janssen Alzheimer Immunotherapy Research \& Development, LLC.; Johnson \& Johnson Pharmaceutical Research \& Development LLC.; Lumosity; Lundbeck; Merck \& Co., Inc.; Meso Scale Diagnostics, LLC.; NeuroRx Research; Neurotrack Technologies; Novartis Pharmaceuticals Corporation; Pfizer Inc.; Piramal Imaging; Servier; Takeda Pharmaceutical Company; and Transition Therapeutics. The Canadian Institutes of Health Research is providing funds to support ADNI clinical sites in Canada. Private sector contributions are facilitated by the Foundation for the National Institutes of Health (www.fnih.org). The grantee organization is the Northern California Institute for Research and Education, and the study is coordinated by the Alzheimer's Therapeutic Research Institute at the University of Southern California. ADNI data are disseminated by the Laboratory for Neuro Imaging at the University of Southern California. The investigators within the ADNI contributed to the design and implementation of ADNI and/or provided data but did not participate in analysis or writing of this report. A complete listing of ADNI investigators can be found at: http: //adni.loni.usc.edu/wp-content/uploads/how_to_apply/ADNI_Acknowledgement_List.pdf.
\end{abstract}

Conflicts of Interest: The authors declare no conflict of interest.

\title{
References
}

1. Weller, J.; Budson, A. Current understanding of Alzheimer's disease diagnosis and treatment. F1000Research $2018,7,1161$. [CrossRef] [PubMed]

2. Lumsden, A.L.; Mulugeta, A.; Zhou, A.; Hyppönen, E. Apolipoprotein E (APOE) genotype-associated disease risks: A phenomewide, registry-based, case-control study utilising the UK Biobank. EBioMedicine 2020, 59, 102954. [CrossRef] [PubMed]

3. Huebbe, P.; Rimbach, G. Evolution of human apolipoprotein E (APOE) isoforms: Gene structure, protein function and interaction with dietary factors. Ageing Res. Rev. 2017, 37, 146-161. [CrossRef] [PubMed]

4. Kang, J.H.; Logroscino, G.; De Vivo, I.; Hunter, D.; Grodstein, F. Apolipoprotein E, cardiovascular disease and cognitive function in aging women. Neurobiol. Aging 2005, 26, 475-484. [CrossRef]

5. Phillips, M.C. Apolipoprotein E isoforms and lipoprotein metabolism. IUBMB Life 2014, 66, 616-623. [CrossRef]

6. Riedel, B.C.; Thompson, P.M.; Brinton, R.D. Age, APOE and sex: Triad of risk of Alzheimer's disease. J. Steroid. Biochem. Mol. Biol. 2016, 160, 134-147. [CrossRef]

7. Wolf, A.B.; Caselli, R.J.; Reiman, E.M.; Valla, J. APOE and neuroenergetics: An emerging paradigm in Alzheimer's disease. Neurobiol. Aging 2013, 34, 1007-1017. [CrossRef]

8. Huang, Y.; Mahley, R.W. Apolipoprotein E: Structure and function in lipid metabolism, neurobiology, and Alzheimer's diseases. Neurobiol. Dis. 2014, 72, 3-12. [CrossRef]

9. Getz, G.; Reardon, C. Apoprotein E and Reverse Cholesterol Transport. Int. J. Mol. Sci. 2018, 19, 3479. [CrossRef]

10. Mur, J.; McCartney, D.L.; Walker, R.M.; Campbell, A.; Bermingham, M.L.; Morris, S.W.; Porteous, D.J.; McIntosh, A.M.; Deary, I.J.; Evans, K.L.; et al. DNA methylation in APOE: The relationship with Alzheimer's and with cardiovascular health. Alzheimer's Dement. Transl. Res. Clin. Interv. 2020, 6, e12026. [CrossRef]

11. Langsted, A.; Freiberg, J.J.; Nordestgaard, B.G. Fasting and Nonfasting Lipid Levels. Circulation 2008, 118, 2047-2056. [CrossRef]

12. Mahley, R.W. Apolipoprotein E: From cardiovascular disease to neurodegenerative disorders. J. Mol. Med. 2016, 94, 739-746. [CrossRef]

13. Dominiczak, M.H.; Caslake, M.J. Apolipoproteins: Metabolic role and clinical biochemistry applications. Ann. Clin. Biochem. Int. J. Lab. Med. 2011, 48, 498-515. [CrossRef]

14. Davel, A.P.; Wenceslau, C.F.; Akamine, E.H.; Xavier, F.E.; Couto, G.K.; Oliveira, H.T.; Rossoni, L.V. Endothelial dysfunction in cardiovascular and endocrine-metabolic diseases: An update. Braz. J. Med. Biol. Res. 2011, 44, 920-932. [CrossRef] 
15. Chang, T.-Y.; Yamauchi, Y.; Hasan, M.T.; Chang, C. Cellular cholesterol homeostasis and Alzheimer's disease. J. Lipid Res. 2017, 58, 2239-2254. [CrossRef]

16. Belloy, M.E.; Napolioni, V.; Greicius, M.D. A Quarter Century of APOE and Alzheimer's Disease: Progress to Date and the Path Forward. Neuron 2019, 101, 820-838. [CrossRef]

17. Kotze, M.J.; Van Rensburg, S.J. Pathology supported genetic testing and treatment of cardiovascular disease in middle age for prevention of Alzheimer's disease. Metab. Brain. Dis. 2012, 27, 255-266. [CrossRef]

18. Levi, O.; Dolev, I.; Belinson, H.; Michaelson, D.M. Intraneuronal amyloid- $\beta$ plays a role in mediating the synergistic pathological effects of apoE4 and environmental stimulation. J. Neurochem. 2007, 103, 1031-1040. [CrossRef]

19. Martins, I.J.; Hone, E.; Foster, J.K.; Sünram-Lea, S.I.; Gnjec, A.; Fuller, S.J.; Nolan, D.; Gandy, S.E.; Martins, R.N. Apolipoprotein E, cholesterol metabolism, diabetes, and the convergence of risk factors for Alzheimer's disease and cardiovascular disease. Mol. Psychiatry 2006, 11, 721-736. [CrossRef]

20. Greenberg, S.M.; Bacskai, B.J.; Hernandez-Guillamon, M.; Pruzin, J.; Sperling, R.; Van Veluw, S.J. Cerebral amyloid angiopathy and Alzheimer disease-One peptide, two pathways. Nat. Rev. Neurol. 2020, 16, 30-42. [CrossRef]

21. Jochemsen, H.M.; Teunissen, C.E.; Ashby, E.L.; Van der Flier, W.M.; Jones, R.E.; Geerlings, M.I.; Scheltens, P.; Kehoe, P.G.; Muller, M. The association of angiotensin-converting enzyme with biomarkers for Alzheimer's disease. Alzheimers Res. 2014, 6, 27. [CrossRef]

22. Rusek, M.; Pluta, R.; Ułamek-Kozioł, M.; Czuczwar, S.J. Ketogenic Diet in Alzheimer’s Disease. Int. J. Mol. Sci. $2019,20,3892$. [CrossRef]

23. Nakamura, A.; Kaneko, N.; Villemagne, V.L.; Kato, T.; Doecke, J.; Doré, V.; Fowler, C.; Li, Q.-X.; Martins, R.; Rowe, C.; et al. High performance plasma amyloid- $\beta$ biomarkers for Alzheimer's disease. Nature 2018, 554, 249-254. [CrossRef]

24. Poirier, J. Apolipoprotein E and Alzheimer's Disease A Role in Amyloid Catabolism. Ann. N. Y. Acad. Sci. 2006, 924, 81-90. [CrossRef]

25. Dlugosz, P.; Nimpf, J. The Reelin Receptors Apolipoprotein E receptor 2 (ApoER2) and VLDL Receptor. Int. J. Mol. Sci. 2018, 19, 3090. [CrossRef]

26. Isbir, T.; Agaçhan, B.; Yilmaz, H.; Aydin, M.; Kara, I.; Eker, D.; Eker, E. Interaction between apolipoprotein-E and angiotensinconverting enzyme genotype in Alzheimer's disease. Am. J. Alzheimer's Dis. Other Dement. 2001, 16, 205-210. [CrossRef]

27. Arpa, A.; Del Ser, T.; Goda, G.; Barba, R.; Bornstein, B. Apolipoprotein E, angiotensin-converting enzyme and $\alpha-1-$ antichymotrypsin genotypes are not associated with post-stroke dementia. J. Neurol. Sci. 2003, 210, 77-82. [CrossRef]

28. Qiu, W.W.Q.; Lai, A.; Mon, T.; Mwamburi, M.; Taylor, W.; Rosenzweig, J.; Kowall, N.; Stern, R.; Zhu, H.; Steffens, D.C. Angiotensin Converting Enzyme Inhibitors and Alzheimer Disease in the Presence of the Apolipoprotein E4 Allele. Am. J. Geriatr. Psychiatry 2014, 22, 177-185. [CrossRef]

29. Renee Ruhaak, L.; Van Der Laarse, A.; Cobbaert, C.M. Apolipoprotein profiling as a personalized approach to the diagnosis and treatment of dyslipidaemia. Ann. Clin. Biochem. Int. J. Lab. Med. 2019, 56, 338-356. [CrossRef]

30. Tamburus, N.Y.; Verlengia, R.; Kunz, V.C.; César, M.C.; Silva, E. Apolipoprotein B and angiotensin-converting enzyme polymorphisms and aerobic interval training: Randomized controlled trial in coronary artery disease patients. Braz. J. Med. Biol. Res. 2018, 51. [CrossRef]

31. De Vries, M.A.; Van Santen, S.S.; Klop, B.; Van Der Meulen, N.; Van Vliet, M.; Van De Geijn, G.-J.M.; Van Der Zwan-Van Beek, E.M.; Birnie, E.; Liem, A.H.; De Herder, W.W.; et al. Erythrocyte-bound apolipoprotein B in atherosclerosis and mortality. Eur. J. Clin. Investig. 2017, 47, 289-296. [CrossRef] [PubMed]

32. Hwang, Y.-C.; Ahn, H.-Y.; Han, K.H.; Park, S.-W.; Park, C.-Y. Prediction of future cardiovascular disease with an equation to estimate apolipoprotein B in patients with high cardiovascular risk: An analysis from the TNT and IDEAL study. Lipids Health Dis. 2017, 16, 158. [CrossRef] [PubMed]

33. McKhann, G.; Drachman, D.; Folstein, M.; Katzman, R.; Price, D.; Stadlan, E.M. Clinical diagnosis of Alzheimer's disease: Report of the NINCDS-ADRDA Work Group under the auspices of Department of Health and Human Services Task Force on Alzheimer's Disease. Neurology 1984, 34, 939-944. [CrossRef] [PubMed]

34. Iglewicz, B.; Hoaglin, D. The ASQC Basic References in Quality Control: Statistics Techniques. In How Detect Handle Outliers; Mykyta, E.F., Ed.; ASQC Quality Press: Milwaukee, WI, USA, 1993; Volume 16.

35. Aggarwal, V.; Kosian, S. Feature Selection and Dimension Reduction Techniques in SAS; EXL Service: New York, NY, USA, 2011.

36. Kehoe, P.G.; Wong, S.; Al Mulhim, N.; Palmer, L.E.; Miners, J.S. Angiotensin-converting enzyme 2 is reduced in Alzheimer's disease in association with increasing amyloid- $\beta$ and tau pathology. Alzheimer's Res. Ther. 2016, 8, 50. [CrossRef]

37. Yasar, S.; Varma, V.R.; Harris, G.C.; Carlson, M.C. Associations of Angiotensin Converting Enzyme-1 and Angiotensin II Blood Levels and Cognitive Function. J. Alzheimer's Dis. 2018, 63, 655-664. [CrossRef]

38. Yang, Y.-H.; Liu, C.-K. Angiotensin-Converting Enzyme Gene in Alzheimer's Disease. Tohoku. J. Exp. Med. 2008, 215, 295-298. [CrossRef]

39. Hussain, A.; Tang, O.; Sun, C.; Jia, X.; Selvin, E.; Nambi, V.; Folsom, A.; Heiss, G.; Zannad, F.; Mosley, T.; et al. Soluble AngiotensinConverting Enzyme 2, Cardiac Biomarkers, Structure, and Function, and Cardiovascular Events (from the Atherosclerosis Risk in Communities Study). Am. J. Cardiol. 2021, 146, 15-21. [CrossRef]

40. Liang, Y.; Deng, H.; Bi, S.; Cui, Z.; Lata, A.; Zheng, D.; Wang, Y. Urinary angiotensin converting enzyme 2 increases in patients with type 2 diabetic mellitus. Kidney Blood Press. Res. 2015, 40, 101-110. [CrossRef] 
41. Najm, R.; Jones, E.A.; Huang, Y. Apolipoprotein E4, inhibitory network dysfunction, and Alzheimer's disease. Mol. Neurodegener. 2019, 14, 24. [CrossRef]

42. Raman, S.; Brookhouser, N.; Brafman, D.A. Using human induced pluripotent stem cells (hiPSCs) to investigate the mechanisms by which Apolipoprotein E (APOE) contributes to Alzheimer's disease (AD) risk. Neurobiol. Dis. 2020, 138, 104788. [CrossRef]

43. Lim, W.L.; Martins, I.J.; Martins, R.N. The involvement of lipids in Alzheimer's disease. J. Genet. Genom. 2014, 41, 261-274. [CrossRef]

44. Kajiwara, Y.; Wang, E.; Wang, M.; Sin, W.C.; Brennand, K.J.; Schadt, E.; Naus, C.C.; Buxbaum, J.; Zhang, B. GJA1 (connexin43) is a key regulator of Alzheimer's disease pathogenesis. Acta. Neuropathol. Commun. 2018, 6, 144. [CrossRef]

45. Rawat, V.; Wang, S.; Sima, J.; Bar, R.; Liraz, O.; Gundimeda, U.; Parekh, T.; Chan, J.; Johansson, J.O.; Tang, C.; et al. ApoE4 Alters ABCA1 Membrane Trafficking in Astrocytes. J. Neurosci. 2019, 39, 9611-9622. [CrossRef]

46. Liu, S.; Liu, J.; Weng, R.; Gu, X.; Zhong, Z. Apolipoprotein E gene polymorphism and the risk of cardiovascular disease and type 2 diabetes. BMC Cardiovasc. Disord. 2019, 19, 213. [CrossRef]

47. Safieh, M.; Korczyn, A.D.; Michaelson, D.M. ApoE4: An emerging therapeutic target for Alzheimer's disease. BMC Med. 2019, 17, 64. [CrossRef]

48. Tzoulaki, I.; Castagné, R.; Boulangé, C.L.; Karaman, I.; Chekmeneva, E.; Evangelou, E.; Ebbels, T.M.D.; Kaluarachchi, M.R.; Chadeau-Hyam, M.; Mosen, D.; et al. Serum metabolic signatures of coronary and carotid atherosclerosis and subsequent cardiovascular disease. Eur. Heart J. 2019, 40, 2883-2896. [CrossRef]

49. Soares, H.D. Plasma Biomarkers Associated With the Apolipoprotein E Genotype and Alzheimer Disease. Arch. Neurol. 2012, 69, 1310. [CrossRef]

50. Gigante, B.; Leander, K.; Vikstrom, M.; Frumento, P.; Carlsson, A.C.; Bottai, M.; De Faire, U. Elevated ApoB serum levels strongly predict early cardiovascular events. Heart 2012, 98, 1242-1245. [CrossRef]

51. Walldius, G.; Jungner, I.; Holme, I.; Aastveit, A.H.; Kolar, W.; Steiner, E. High apolipoprotein B, low apolipoprotein A-I, and improvement in the prediction of fatal myocardial infarction (AMORIS study): A prospective study. Lancet 2001, 358, 2026-2033 [CrossRef]

52. Kastelein, J.J.P.; Van Der Steeg, W.A.; Holme, I.; Gaffney, M.; Cater, N.B.; Barter, P.; Deedwania, P.; Olsson, A.G.; Boekholdt, S.M.; Demicco, D.A.; et al. Lipids, Apolipoproteins, and Their Ratios in Relation to Cardiovascular Events with Statin Treatment. Circulation 2008, 117, 3002-3009. [CrossRef]

53. Sniderman, A.D.; Thanassoulis, G.; Glavinovic, T.; Navar, A.M.; Pencina, M.; Catapano, A.; Ference, B.A. Apolipoprotein B Particles and Cardiovascular Disease. JAMA Cardiol. 2019, 4, 1287. [CrossRef]

54. Shih, Y.H.; Tsai, K.J.; Lee, C.W.; Shiesh, S.C.; Chen, W.T.; Pai, M.C.; Kuo, Y.M. Apolipoprotein C-III is an amyloid- $\beta$-binding protein and an early marker for Alzheimer's disease. J. Alzheimer's Dis. 2014, 41, 855-865. [CrossRef]

55. Rehiman, S.H.; Lim, S.M.; Neoh, C.F.; Majeed, A.B.A.; Chin, A.V.; Tan, M.P.; Kamaruzzaman, S.B.; Ramasamy, K. Proteomics as a reliable approach for discovery of blood-based Alzheimer's disease biomarkers: A systematic review and meta-analysis. Ageing Res. Rev. 2020, 60, 101066. [CrossRef]

56. Bahrami, A.; Barreto, G.E.; Lombardi, G.; Pirro, M.; Sahebkar, A. Emerging roles for high-density lipoproteins in neurodegenerative disorders. Biofactors 2019, 45, 725-739. [CrossRef]

57. Guo, T.; Yin, R.X.; Li, H.; Wang, Y.M.; Wu, J.Z.; Yang, D.Z. Association of the Trp316Ser variant (rs1801690) near the apolipoprotein $\mathrm{H}$ (ß2-glycoprotein-I) gene and serum lipid levels. Int. J. Clin. Exp. Pathol. 2015, 8, 7291-7304.

58. Mather, K.A.; Thalamuthu, A.; Oldmeadow, C.; Song, F.; Armstrong, N.J.; Poljak, A.; Holliday, E.G.; McEvoy, M.; Kwok, J.B.; Assareh, A.A.; et al. Genome-wide significant results identified for plasma apolipoprotein $\mathrm{H}$ levels in middle-aged and older adults. Sci. Rep. 2016, 6, 23675. [CrossRef]

59. Mattsson, N.; Insel, P.; Nosheny, R.; Trojanowski, J.Q.; Shaw, L.M.; Jack, C.R.; Tosun, D.; Weiner, M. Effects of cerebrospinal fluid proteins on brain atrophy rates in cognitively healthy older adults. Neurobiol. Aging 2014, 35, 614-622. [CrossRef] [PubMed]

60. Ding, Q.; Shults, N.V.; Gychka, S.G.; Harris, B.T.; Suzuki, Y.J. Protein Expression of Angiotensin-Converting Enzyme 2 (ACE2) is Upregulated in Brains with Alzheimer's Disease. Int. J. Mol. Sci. 2021, 22, 1687. [CrossRef] [PubMed]

61. Ignjatovic, V.; Geyer, P.E.; Palaniappan, K.K.; Chaaban, J.E.; Omenn, G.S.; Baker, M.S.; Deutsch, E.W.; Schwenk, J.M. Mass Spectrometry-Based Plasma Proteomics: Considerations from Sample Collection to Achieving Translational Data. J. Proteome Res. 2019, 18, 4085-4097. [CrossRef] [PubMed]

62. Hsieh, H.; Boehm, J.; Sato, C.; Iwatsubo, T.; Tomita, T.; Sisodia, S.; Malinow, R. AMPAR Removal Underlies A $\beta$-Induced Synaptic Depression and Dendritic Spine Loss. Neuron 2006, 52, 831-843. [CrossRef] [PubMed] 